\title{
¿Qué Nombre tendremos ahora? Los apocalípticos problemas de las identidades y la ciudad
}

Gilbert Ulloa Brenes*

\section{RESUMEN}

En este artículo el autor reflexiona sobre el tema de la identidad asumida en determinados contextos socioculturales y su manifestación en la concepción de ciudad, tanto en la tradición bíblica como en el escenario de la denominada sociedad del conocimiento. Para ello, y con base en algunos conceptos psicoanalíticos, se elaboran una serie de consideraciones de orden sociocultural a partir de los capítulos 21 y 22 del Apocalipsis, para luego trasladarlas hacia la sociedad del siglo XXI y el tipo de experiencias ciudadanas que en ella se presentarían.

Palabras clave: Cultura, identidad, tradición bíblica, sociedad del conocimiento.

\section{ABSTRACT}

In this article the author reflects about the assuming identity in determine social and cultural contexts and its expressions in the city conception, also from the biblical tradition to the so called society of knowledge. Therefore, based on psychoanalytic concepts he creates a new consideration for social-cultural order from the Revelations book, chapters 21 and 22, to confront it with the XXI society behavior and experiences.

Keywords: Culture, identity, biblical tradition, knowledge society.

Máster en Estudios de Cultura Centroamericana y licenciado en Psicología. Productor académico en la Universidad Estatal a Distancia y docente en la Universidad Nacional. Ha publicado artículos sobre cultura, sociedad y educación en diferentes revistas especializadas de la Universidad de Costa Rica y la Universidad Nacional. 


\section{Introducción}

\section{Identidad y cultura}

El problema de las identidades ${ }^{1}$ puede rastrearse en diferentes expresiones culturales antiguas $\mathrm{o}$ contemporáneas, y servirnos para reflexionar en torno a las características de los procesos culturales que nos corresponde vivir.

Siguiendo esta premisa, trataremos aquí de abstraer algunas consideraciones sobre el trasfondo sociocultural bíblico a partir de los capítulos 21 y 22 del Apocalipsis, para luego trasladarlas hacia la sociedad del siglo XXI.

El puente que nos permitirá movernos de un escenario al otro será el concepto de ciudad, en cuanto espacio cultural en el que las identidades acaecen ${ }^{2}$, entendidas estas desde una concepción basada en el psicoanálisis.

De entrada consideramos que la cultura y sus sistemas simbólicos han prefigurado la vida y el mundo en diferentes períodos históricos. De ahí que esta prefiguración simbólica de lo real lo es también de la disposición y construcción de los espacios en los que se desarrolla la vida cotidiana (las ciudades, por ejemplo) y, claro está, de las identidades en tanto que estructuraciones de los sujetos.

En esta primera década del siglo XXI, con todo y la aparente crisis de muchas certezas otrora incuestionables y el advenimiento de la llamada sociedad del conocimiento, el tema de la identidad y su relación con los elementos simbólicos culturales resulta crucial, pues las identidades no son substancias ni inmutables ni eternas. Quizá todo lo contrario, serán conflictivas, inestables, cambiantes.

\section{La identidad: lo simbólico y el deseo}

Precisamente, el modelo psicoanalítico lacaniano provee una visión del sujeto que hace ruptura contra todo esencialismo inmanente, postulando más bien la altísima dependencia de la alteridad y, especialmente, del lenguaje, registro de lo simbólico, como principal elemento en la estructuración de las subjetividades.

1. Identidad como reconocimiento del sujeto a partir de su posición en la estructura social, así como a su ubicación en categorías biopsicológicas (sexo, edad), grupales (étnica, nacional), de roles sociales (familiares, profesionales, institucionales) o de afiliación ideológica (iglesias, partidos, movimientos sociales) (Hernández, 1996: 396) y mediatizada por el frecuente encuentro de un otro cultural.

2. La ciudad, como espacio sociocultural, será un conjunto delimitado y centralizado de relaciones sociales con sentido, expresado espacialmente en términos arquitectónicos y de distribución de lugares (Malina, 2000: 44-45). No se trata de un conjunto estático, sino, más bien, un conjunto de procesos de intercambios de bienes, servicios y mensajes (Nivón, 2000: 115). 
Ya en la relación triádica hijomadre-padre, una especie de protoidentidad del sujeto (hijo) aparece confundida con la figura materna, y no es sino hasta la irrupción del padre que el sujeto adviene a dos dimensiones: a lo inconsciente (reprimido) y a lo cultural (simbólico). De ahí el postulado lacaniano donde lo inconsciente es susceptible de leerse como un lenguaje (Lacan. 2005: 227-310).

Si una cierta "identidad" le es dada al sujeto, ésta provendrá del lenguaje, de los símbolos culturalmente instituidos. Así, el sujeto del inconsciente será una serie de acontecimientos del lenguaje pues nunca contiene significados últimos. Por esto no hay identidad coherente o auténtica, sino solo un cierto "sentido" de identidad, una metáfora del "ser", es decir, un significante que ocupa el lugar de otro (Lacan. 2005: 867-870), y aunque el yo sea culturalmente funcional, inconscientemente es precario: el lenguaje define y al mismo tiempo no define.

Nada podrá luego suturar la original pérdida del seno materno con el cual el individuo se hallaba unido imaginariamente de manera indiferenciada. La consecuente identificación con la alteridad legal del lenguaje en cuanto inconsciente travesía por la cultura, estará así matizada por la búsqueda del sustituto simbólico de aquella fantasía de plenitud y unión. Es a partir de ahí donde la contradicción entre inconsciente y cultura aparece en su perturbadora y creativa dinámica: el deseo.

Con la irrupción de la legalidad cultural (el Nombre del Padre), el sujeto es sacado del mundo extático donde él y el seno materno son idénticos; es castrado de aquella unificación erótica adviniendo ahora, con su entrada en la cultura, a la dimensión del deseo.

La libido del sujeto antes indiferenciada será subordinada a las nominaciones y canalizaciones culturalmente admisibles por medio del lenguaje ( $Y O$ es mujer e hija, $Y O$ es hombre e hijo). Con la entrada en el orden simbólico, el lenguaje determinará ahora tanto la identidad como el deseo (Sarup. 1993: 20-24).

En el lenguaje se articulan demandas ${ }^{3}$, pero su significado inconsciente "[...] no es intrínseco sino que está particularmente determinado por la respuesta del otro hacia la demanda." (Sarup. 1993: 20; traducción nuestra). Por eso la aparición del deseo en la demanda es precaria y dependiente del reconocimiento que de tal demanda hagan los otros.

3. En el sentido de demandar del otro reconocimiento: tal es el caso, en una metáfora romántica, de la teratológica búsqueda por reconocimiento de la criatura del Dr. Frankenstein. 
Así, el "sentido" del mundo nos viene dado por el lenguaje (lo simbólico cultural), siendo nosotros (en nuestra originante pérdida) a la vez identificados por él. Pero la forma en que el lenguaje en tanto registro simbólico nos designa, es precario, y en ese proceso dependemos del reconocimiento de los otros y la ambigüedad de su lenguaje.

El sentido-de-la-identidad, estable y precario a la vez, posibilita percatarnos del lugar de los otros y, a través de ellos, del sí mismo. Ese sentido-de-laidentidad va a estar constituido a partir de discursos legalizados, emitidos desde las instancias culturales que predefinen el mundo: las instituciones dentro de las cuales experimentamos los parámetros, roles y funciones del yo que somos y que penetran de sentido ordinal nuestras identidades.

\section{Instituciones Culturales}

Los símbolos que en forma de discursos sostienen las identidades humanas, están avalados desde instituciones culturales. Por lo común estas instituciones reguladoras de lo simbólico tratan de suturar la fisura de sentido que hay entre los significantes y los significados. Así, las instituciones culturales articulan diversos sentidos para "instituirlos" como leyes que regulen el sentido-de-la-identidad.

Esos discursos serían vehículos en la configuración del "nosotros", es decir, del "yo" que se asimila en los "otros" a manera del reflejo en un espejo. A partir de estos discursos institucionalizados que asumimos como "nuestros", el precario sentido-de-laidentidad irá adquiriendo estabilidad hasta tornarse en algo relativamente incuestionable, ofreciendo al yo la posibilidad de aparecer y moverse de forma adecuada en una cultura determinada: actuar determinados roles, aspirar a determinados valores propios de la cultura en la cual se ha configurado nuestra identidad.

Tales discursos podemos entenderlos como elaboraciones de carácter simbólico que permiten a diversos individuos relacionarse en torno a temas vinculantes. Por esto, el sentido-de-la-identidad asumido permite al sujeto actuar roles y funciones en determinadas condiciones. Pero si los discursos pierden su capacidad vinculante, las identidades basadas en ellos amanecen a la crisis, pues la realidad deja de aparecer estable y, seguramente, las acciones requerirán de otros discursos, los cuales conllevarían cambios en las identidades. Florece la incertidumbre sobre el nombre con que otrora el sujeto era conocido.

\section{Desarrollo}

\section{Algunos elementos sobre la sociedad del siglo I en el Mediterráneo}

Las sociedades mediterráneas del siglo I eran también sociedades en 
constante crisis. El imperio de Roma sobre la mayor parte del mundo conocido entonces, reñía, en términos culturales, con la mayoría de las instituciones culturales de sociedades como la judía. Algunos judíos soñaban con la reestructuración del orden que conocieran antes del dominio romano, pero otros predicaban y esperaban el advenimiento de un orden radicalmente nuevo en el que incluso el viejo estado de cosas, previo a Roma, quedaría atrás.

Este tipo de preocupaciones se puede percibir en el discurso de diversos textos del Testamento Cristiano: Cartas de Pablo, Cartas de Juan, Apocalipsis; textos cuyo sentido guarda relación con el sistema social originario y los patrones de lenguaje vigentes ahí, por lo que es menester ensayar la reconstrucción del sistema social en que estos fueron elaborados para fundamentar la actividad del lector actual. Intentemos entonces tal reconstrucción.

\section{Sistema social del siglo I}

Según Stegemann y Stegemann (2001: 19-28) se trataba de una sociedad agrícola avanzada, fundada en el cultivo de tierras como sistema productivo $\mathrm{y}$ en el control de los bienes por parte de grupos reducidos. La mayoría de sus habitantes eran labradores, y los factores productivos más importantes eran la posesión de tierra, así como el trabajo de cultivadores directos, arrendatarios y/o jornaleros, más o menos dependientes. En este tipo de sociedad las dimensiones campo-ciudad estaban poco separadas, formando una realidad, en este sentido, de características predominantemente rurales.

Así, en las ciudades de este periodo, se realizaban actividades artesanales, de comercio y administración de lo producido en el campo. En ellas habitaban las élites que dominaban casi todos los aspectos de la vida social, la propiedad de bienes y tierras, así como el control político y religioso.

No obstante el bajo porcentaje de población urbana de la época, el poder se concentraba en los centros citadinos, teniendo esta concentración repercusiones de carácter simbólico, sobre todo, como señala Malina (1995: 115-120), en la delimitación y conservación del status social. El poder de la época recaía sobre una población selecta (y minoritaria) cuyo status alto no necesariamente guardaba relación con la riqueza, dado que: "[...] los miembros de la élite ciudadana basaban su estatus en el nacimiento; como pertenecían a buenas familias, gozaban de poder, propiedades $\mathrm{y}$ ciertos atributos personales muy valorados, pues los escritos del Antiguo Testamento legitimaban en gran medida su posición" (Malina, 1995: 117-118).

Estas élites se consideraban portadoras de una "gran tradición" cultural, y como tales, se erigían garantes de la solidez y el orden sociocultural establecido. Esto legitimaba su control político. Quienes no pertenecían a las élites citadinas (cerca del $98 \%$ de la población) mantenían, empero, una relación social 
de identidad con la ciudad, tendiendo, los miembros de status bajo y los campesinos, a la imitación de los usos elitistas más o menos adaptados a las diferentes condiciones, buscando así conformarse como grupos portadores de una "pequeña tradición" cultural.

El mantenimiento del honor era un valor central en estas sociedades. $\mathrm{Si}$ el status estaba referido a la diferenciada posición social entre sujetos pertenecientes a un mismo sistema, en las sociedades mediterráneas del siglo I este se adquiría por nacimiento y quedaba patente en el honor y el prestigio acumulados. Así, la persona honorable vivía en arreglo a su status, sabía cómo protegerlo cumpliendo con las obligaciones de su posición y preocupándose de sus asuntos. Se trataba a toda costa de mantener el honor de la imagen personal basada en la imagen social de la gran familia a la que los sujetos pertenecían (Malina, 1995). Los pobres, en cambio, eran aquellos que no podían mantener su status familiar heredado, condición que les acarreaba pérdida de honor y caída en desgracia.

\section{La polis o civitates}

En el marco general de este tipo de sociedad, la ciudad era el lugar central administrativo. Todos los caminos locales debían conectar con la ciudad, al ser ésta el centro vital de la sociedad.

Sus moradores preeminentes eran en su mayoría terratenientes que formaban parte de la élite o personas estimadas por dicha élite. Estos estaban controlados por el Imperio y controlaban, a su vez, la producción agrícola y otros productos básicos.

Por lo común, la población citadina estaba conformada por funcionarios, sacerdotes, estudiosos, escribanos, comerciantes, siervos, soldados, artesanos, obreros, mendigos y una élite restringida de terratenientes que vivían de las rentas o cargos políticos. La clase dirigente del sistema se concentraba en la ciudad, constituyendo apenas el $2 \%$ de la población.

Estas ciudades no tenían características completamente urbanas, sino que se trataba de lugares llamados polis o civitates $^{4}$.

Las características comunes de las ciudades antiguas incluirían los siguientes aspectos: eran el lugar central dentro de una región donde se podían reconocer redes de relaciones sociales; por ello, aparecían en forma de puntos centrípetas, pues todas las poblaciones de la región dirigían sus intereses hacia ellas; así, todos los caminos de las villas y poblados en la región conducían a la ciudad, con lo que se perfilaba la pertenencia a

4. La polis era en la antigua Grecia un estado autónomo conformado por la ciudad y un pequeño territorio de características rurales, mientras que civitates es el vocablo latino para referirse a este tipo de "ciudades". 
una ciudad terminal como ciudad madre o metrópolis.

Con esto, la ciudad ofrecía una referencia efectiva para la organización, no solo de los territorios y las actividades, sino también de las identidades. El pertenecer a una ciudad u otra, el ser jerosolimitano o samaritano, por ejemplo, marcaba la condición social y cultural de las personas.

Por ello, ser miembro de alguna ciudad comprendía, principalmente, la pertenencia y la capacidad de establecer relaciones con las élites y otros residentes de la ciudad, es decir, ser reconocido por ellos como ciudadano e hijo de alguna familia importante.

En las ciudades de la antigüedad, lo religioso y lo económico estaban fuertemente vinculados a las instituciones del parentesco y la política; por ello, las reglas, metas y valores políticos (por lo común propias de las familias de élite) servían para configurar las expresiones religiosas en el espacio público. Los sistemas de impuestos y tributos articulaban religión y economía en pro de las élites sacerdotales y administrativas.

El Templo cumplía una importante función en este aspecto, al ser el lugar físico donde se concentraban actividades de carácter político, tradicional y económico, sobre todo si se trataba de una ciudad con fundamentos teocrático-monárquicos.

Entre la población, que estaba bien estratificada, según vimos antes, aquellos ocupantes de los lugares superiores solían ejercer un "poder sagrado" sobre los subalternos, y cualquier perjuicio cometido contra esos superiores se consideraba una suerte de sacrilegio.

Tal como informa Malina (2000: 40-43), las únicas dos instituciones explícitas y formales de esa época presentes en la ciudad eran el parentesco y la política. Incluso la religión estaba vinculada con lo doméstico y lo político: los funcionarios religiosos solían ser personajes políticos y domésticos a la vez.

Al no haber durante esta época Naciones o Estados, la procedencia de cada persona estaba, pues, fuertemente vinculada a las metrópolis: "grandes" ciudades primarias rodeadas por pequeños poblados que veían en ellas un punto central de gran significación.

\section{Primeras comunidades cristianas: la ekklesia y la Nueva Jerusalén}

Las comunidades de creyentes en Cristo habrían sido, en ese contexto, grupos de carácter sectario no adscritos a la tradición judía ni a la oficialidad greco-romana; más bien eran grupos cuyos miembros de procedencia campesina estaban desvinculados de las élites urbanas (Malina, 1995: 119). Esto hacía de los creyentes en Cristo verdaderos desposeídos en términos culturales. 
Stegemann y Stegemann (2001: 339-354) proponen distinguir, conceptualmente, a las comunidades creyentes en Cristo de los seguidores de Jesús en Israel a partir de cuatro rasgos:

1. Dichas comunidades estuvieron compuestas de judíos y, paulatinamente, en especial por un buen número de creyentes provenientes del "paganismo".

2. Entre judíos y no-judíos se establecían relaciones sociales ilimitadas.

3. Estas comunidades existieron como grupos minoritarios dentro de mayorías "paganas" en las diferentes ciudades del Imperio Romano.

4. Y existieron junto y además de los representantes del judaísmo fuera de Israel. En este sentido, estas comunidades no pertenecían al judaísmo ni se comprendían como parte del paganismo greco-romano.

Estas comunidades habrían nacido por la expulsión de Jerusalén de algunos miembros de entre los creyentes en Cristo dentro de Israel que pronto conquistarían, en otras ciudades, nuevos seguidores.

El término ekklesia sería el más importante en el contexto neotestamentario para hablar de aquellas comunidades creyentes en Cristo, pues refiere al tipo de entidad social en la que, reunidas varias personas, creaban para su grupo un ambiente de comunidad (Stegemann y Stegemann, 2001: 355-390). La ekklesia de las comunidades creyentes tenía finalidades específicas y solía reunirse en casas, por lo que la asistencia de miembros era pequeña ( 40 a 50 personas). Ahí se entablarían relaciones muy personales entre los diferentes creyentes pese a la heterogeneidad y pese a la ausencia de funciones jerarquizadas, aunque las diferentes condiciones socioculturales (circuncisos/ incircuncisos) sí se habrían visto reflejadas en ceremonias comidas y discusiones respecto al honor de cada miembro.

No obstante, se pretendía crear un nuevo orden de relaciones en el que los modelos de honor se trastocaran hasta cierto punto, de manera que todos los creyentes en Cristo pudieran ser reconocidos bajo nuevos criterios de honorabilidad.

Pero las condiciones críticas para el establecimiento de las ekklesias, si bien guardaban alguna relación con algunas disensiones internas, provenían principalmente de conflictos exteriores. Según indican Stegemann y Stegemann (2001: 427-458), en el contexto del "paganismo", los conflictos de los creyentes en Cristo estaban principalmente relacionados con las autoridades imperiales de Roma o algunos sectores de la población, mientras en el judaísmo las comunidades 
cristianas eran vistas como una suerte de secta espuria que amenazaba lo mejor de la gran tradición judía.

De ahí la aspiración por un nuevo orden, que en ese contexto de crisis permitiera no solo renovar las relaciones y el reconocimiento del que podían ser objeto los creyentes cristianos, sino también renovar de forma radical el espacio social y cultural general.

\section{Sobre la Nueva Jerusalén en el Apocalipsis}

Las apocalípticas visiones de Juan relativas al final del orden de cosas de su época y el advenimiento de un nuevo mundo, metaforizan el proceso de cambio por medio de la imagen de una ciudad divina bajada del cielo; es decir, un nuevo centro de vida fundamentalmente divino.

Tal como señala Malina (2000: 45-80), la Nueva Jerusalén que desciende del cielo a la tierra relatada en Apocalipsis 21, 2-9; 27, correspondería al tipo de ciudades propias del medio oriente mediterráneo, ciudades caracterizadas por su establecimiento de origen divino, por la centralidad del templo y el desarrollo de la vida en torno al servicio de la deidad fundante. La visión del profeta Juan incorpora no solo esta concepción de ciudad, sino que además está repleta de representaciones propias de la tradición israelita, comenzando con la tendenciosa ubicación de la visión en una montaña (posiblemente la montaña de la asamblea) donde sobrevendrá luego la Nueva Jerusalén para establecerse sobre la tierra.

El descenso de la nueva ciudad es un acontecimiento cósmico que implicará un cielo nuevo, una tierra nueva y la desaparición del mar. Esta ciudad con su simbólica y refinada arquitectura (ella sería un cubo de oro cristalino, de dimensiones astronómicas ubicada en el punto central de la tierra, siendo toda ella como un gran templo donde morará por siempre Dios) representaría por sí misma el cambio en todas las cosas del mundo. En sus doce cimientos estarán inscritos los nombres de los doce apóstoles; y en sus doce puertas, los nombres de las doce tribus de Israel, quizá insinuando la coincidencia de apóstoles y tribus, o visto de otro modo, insinuando la continuidad que se establecerá entre la tradición veterotestamentaria y los grupos seguidores de Jesús.

Por ello, concluye Malina (2000: 62), la Jerusalén celestial se entiende en tanto acontecimiento cósmico que, descendiendo a la tierra en forma de ciudad, será lugar centrípeta en el complejo general de unas novedosas relaciones humanas, al estilo de las metrópolis en la sociedad del siglo I.

En ella se establecerá el nuevo lugar del poder expresado teocráticamente: un verdadero Reino de Dios, universal, con el Cordero como controlador del cosmos. Dios descenderá 
también desde el cielo para morar en esta Nueva Jerusalén: "el resultado es una experiencia social que serviría como analogía puntual para una deidad más allá de la afinidad étnica" (Malina, 2000: 63). Es una propuesta teocrática que propiciaría el establecimiento de renovados vínculos para toda la humanidad (excepto para aquellos que arderán en el lago de fuego y azufre: Ap. 21:8), bajo una nueva creación, bajo un nuevo orden.

Recordemos que, en efecto, hacia el año 70 Tito, hijo del entonces emperador Vespasiano, ha sitiado la ciudad de Jerusalén con cuatro legiones armadas, después de casi cien años de dominio romano y constantes rebeliones. Ese mismo año son tomados el Templo (incendiado también), el Palacio de Herodes y la parte alta de la ciudad (Escuela Bíblica de Jerusalén, 1975, pp. 1808-1809). Estos eventos habrían sido conocidos por el autor o los autores del Apocalipsis, pues se estima que algunas de sus partes fueron ya compuestas por el año 70, mientras la edición definitiva sería en el 95 (Escuela Bíblica de Jerusalén, 1975, p. 1765).

Quizá estos hechos marcan un punto crucial en la apuesta por la radical novedad en el porvenir del mundo, según el vidente Juan, pues no solo no basta con la reconstrucción de la ciudad, sino que tendrá lugar una completa renovación del cosmos: las cosas no serán más como fueron antes.

\section{¿Quiénes serán los hijos de esta nueva ciudad?}

Con la llegada de la Nueva Jerusalén, la vida se renueva en el principio y en el fin, pues así lo ha dicho a Juan aquél que es “...el Primero y el Último, el que vive" (Apocalipsis 1:17,18). Por consiguiente, la Nueva Jerusalén donde morarán los Vencedores es también principio y fin del mundo.

Pero ¿qué nuevas relaciones socioculturales emergerán ahí? ¿Qué nombre tendrán ahora los habitantes de la Nueva Jerusalén? ¿De dónde se asirán las identidades florecientes? Antiguamente: el mendigo, la mujer, el pobre, el creyente sectario, el trabajador del campo, el sumo sacerdote, los escribas, los ricos, los honorables. Pero en una nueva ciudad cúbica, de oro cristalino, descendida del cielo, ¿cuáles serán sus nombres?

En la visión apocalíptica, esta Nueva Jerusalén es el centro ordenador de la vida, pues: "Las naciones caminarán a su luz, y los reyes de la tierra irán a llevarle su esplendor" (Apocalipsis 21:24). Este sería el sentido centrípeta de una metrópolis adonde todos los caminos llevan.

Se observará así el advenimiento de nuevas identidades para aquellos que morarán en la Ciudad Santa, que tendrán un nuevo Nombre: serán los Vencedores, pertenecerán a una nueva familia y merecerán una nueva heredad. 
En este sentido, será crucial la percepción que los otros tengan tanto del individuo como de la familia a la cual éste pertenece y de la cual es una parte inseparable: esos otros reconocen a aquél individuo como parte del "nosotros" familiar, le dan una existencia significativa. De este modo, en la Nueva Jerusalén los viejos estatutos de reconocimiento se subvierten, dando a sus moradores el Nombre de los Vencedores y un honor asignado en cuanto hijos adoptivos de Dios: "Esta será la herencia del vencedor: yo seré Dios para él, y él será hijo para mí." (Apocalipsis 21:7).

¿Y quién sino Dios podía conferir el más alto honor a aquellos que él reconociera como sus hijos? Los Vencedores a los que se refiere el vidente Juan reciben una nueva identidad emparentada directamente con Dios: comerán del Árbol de la Vida (Apocalipsis 2:7); no padecerán en la segunda muerte (Apocalipsis 2:11); recibirán el maná oculto (Apocalipsis 2:17), poder sobre las naciones y la estrella del alba (Apocalipsis 2:2628 ); se vestirán de blanco (Apocalipsis 3:5); tendrán lugar en el Santuario como columnas (Apocalipsis 3:12) y en el trono de Dios (Apocalipsis 3:21). Nos interesa enfatizar que estos Vencedores tendrán un nombre nuevo desconocido (Apocalipsis 2:17), nombre que permanecerá inscrito en el libro de la vida, siendo reconocidos por Dios-Padre y su séquito angelical (Apocalipsis 3:5): es decir, tendrán una nueva identidad en el linaje de Dios y de la Nueva Jerusalén.

Según las valoraciones de la sociedad del siglo I mediterráneo, podemos hacernos una cierta imagen de los Vencedores: ellos, quizá antes estrangulados por la rigidez del antiguo orden sociocultural, que por el culto a la tradición eran sacrificados con la atadura de los impuestos y con el cuchillo del deshonor, difícilmente reconocidos como hijos de la ciudad o de alguna familia importante, son ahora los hijos predilectos de la Ciudad Santa que ha descendido del cielo y donde mora Dios (sin Templo físico) como el pater familias lo hace en su casa. Sus alimentos serán imperecederos (el Árbol de la Vida, el maná), se vestirán de alegría y poder, viviendo por siempre como una nueva "élite".

\section{Problemas de identidad en la sociedad contemporánea}

El texto apocalíptico nos habla de la llegada de un orden social y cultural diferente, bajo la forma de una nueva ciudad-referente, que en tiempos de crisis logre establecer nuevas relaciones y formas de reconocimiento, es decir, nuevas identidades. ¿Hay ahí alguna metáfora para la situación vivida hoy en nuestras ciudades-referentes?

En los últimos años ha venido reconociéndose desde diversos ámbitos sociales, la inminente llegada de cambios importantes que influirán en la forma en que hemos vivido hasta hoy, 
al punto de hablar del advenimiento de una nueva sociedad, una sociedad dinámica que vivirá de la constante innovación (Corbí, 1996: 52-59), de un fluir informativo que modificará nuestra percepción de la realidad (Morillas, 1994: 6). Esta sociedad ha sido llamada sociedad del conocimiento.

\section{Aspectos generales de la sociedad del conocimiento}

Para Sakaiya, en los países donde el industrialismo ha avanzado más, se está produciendo el paulatino paso de una "Cultura Petrolera" que agoniza, basada en el orden social establecido por la producción industrial y sus respectivos valores éticos, estéticos y culturales, a una "nueva sociedad" donde el bien más abundante será el saber, que en un amplio sentido incluye acepciones como conocimiento e información. Este cambio implicaría el despertar de valoraciones más diversas, subjetivas y fugaces que la antigua estabilidad basada en lo material (Sakaiya, 1995: 55-83).

Entre los "factores disgregadores" que estarían anunciando estos cambios podemos señalar:

1. Grandes avances y abundancia en bienes tecnológicos.

2. Los recursos energéticos (antes tenidos por inagotables) escasean, obligando al ahorro de energía y al cuestionamiento de los antiguos discursos del "desarrollo ilimitado".

3. Acelerado crecimiento poblacional en el mundo.

4. La modificación del "entorno étnico" basado en los ideales de la nación-estado.

5. E importantes cambios en las formas de organización social (Sakaiya, 1995: 131-152).

Así, se trataría del avance hacia una sociedad con escasez de recursos y abundancia de saber, y donde se dará mayor énfasis a la diversificación de los productos que tendrían como valor agregado el "valor-conocimiento" (más de carácter simbólico), es decir, "El valor o precio que una sociedad otorga a aquello que la sociedad reconoce como saber creativo" (Sakaiya. 1995: 226).

Los conceptos de la sociedad industrial decaen, y con ellos las ideologías de las revoluciones industriales. Paulatinamente las categorías industriales van siendo desplazadas con el avance de la "invasión tecnológica" que, según Morillas (1994: 6), modifica los establecimientos antes más o menos sólidos, como las costumbres, el trabajo y la disposición del tiempo libre.

Con ello nacen, en un proceso quizá lento y no sin retrocesos, nuevos principios axiológicos que regirán las expresiones socioculturales de individuos y grupos. Algunos ejes de la nueva axiología que se vislumbran serían: la primacía de los 
valores basados en el conocimiento, la velocidad en el tratamiento, transmisión, búsqueda y valoración de la información, y la interconectividad generadora de relaciones en red (Morillas, 1994: 12-14). Las nuevas certezas de esta sociedad serán procesos de constante creación; ya las verdades no vendrán dadas ni natural ni divinamente.

\section{Ciudad e identidades}

La conectividad organizadora de relaciones en red aplica especialmente en el caso de las ciudades. La mundialización cultural, que corre paralela a la globalización económica, pero con bastante más camino recorrido que ésta, representa uno de los elementos de mayor potencial en la conformación de las ciudades en el nuevo contexto social.

Si las ciudades aparecen como conjuntos de relaciones sociales, donde hay transacciones de bienes, servicios y mensajes, expresados arquitectónica y espacialmente, en el marco de la sociedad del conocimiento éstas se configurarán a partir del cruce de al menos dos tendencias básicas: 1) la confrontación entre el orden local y el orden global; y 2) el contacto de múltiples culturas en relaciones desiguales, todo lo cual permite entrever la ciudad como un proceso en el que se van tejiendo lo multicultural y lo metropolitano como tensión entre centros y periferias (Nivón, 2000: 116-118). Así, "La ciudad actual es más bien un territorio de fragmentación en que la producción económica, la cohesión social, la innovación cultural y la infraestructura de comunicaciones, con frecuencia conspiran contra la integración de la vida urbana" (Nivón, 2000: 118).

Con Nivón (2000: 118-125) podemos hablar en la actualidad de cuatro niveles de ciudades: 1) las ciudades centrales, que refieren a los tradicionales e históricos espacios urbanos integradores de una imagen de centralidad simbólica; 2) las ciudades metropolitanas, que integran además a la periferia, estando legitimadas por su capacidad funcional; 3) las ciudades regionales que, por su importancia, integran otras diferentes ciudades bajo el criterio de la funcionalidad regional; y 4) las ciudades mundiales, establecidas básicamente en países desarrollados e integradas por la convergencia de empresas transnacionales, de habitantes procedentes de diversos contextos y diferentes componentes culturales.

Ninguno de estos cuatro niveles se excluye, aunque esto no implica que en regiones como Centroamérica (Brown, Catalano y Taylor, 2001) se puedan encontrar, por ejemplo, ciudades con características mundiales. Para Nivón, la cultura urbana moderna no es homogénea, sino que tiende al multiculturalismo regido bajo 
ciertos estándares de transmisión masiva, perdiéndose así buena parte de la centralidad imaginaria tradicional (Nivón. 2000: 131-137).

Efectivamente, en las ciudades actuales se dan fuertes procesos de ruptura espacio-relacional que repercuten en las formas de identificación humana. Ello redundaría, según menciona Cilento (2001: 251), en nuevas experiencias de "comunidades imaginadas", comunidades donde los patrones de entrada o salida no se ajustan a patrones tradicionales.

Para las ciudades dentro de la sociedad del conocimiento, el cambio hacia la organización social en red implica necesariamente la búsqueda de interconexiones a nivel mundial, proceso que pone en contacto regiones culturalmente distantes.

En Centroamérica, las ciudades más importantes han establecido conexiones indirectas, sea por la instalación de transnacionales en ellas, por la internacionalización de firmas locales o el establecimiento de fuertes vínculos con ciudades regionales como Miami, que mediatizan los vínculos con otras regiones (Brown, Catalano y Taylor, 2001).

Pero la conectividad supondría un paulatino proceso de modificación de los sistemas simbólicos que configuran las experiencias humanas de fin y principio de siglo. Estas modificaciones ya se han venido presentando con el arribo de medios masivos como la radio y la televisión, y quizá su punto más desarrollado se ha dado con el internet.

Con estos medios masivos de conectividad los límites espaciotemporales cambian y se fortalecen especialmente los límites simbólicos que, de alguna manera, son los únicos capaces ya de posibilitar la construcción de distancias y diferencias ${ }^{5}$.

Además, se han venido configurando, durante las últimas décadas, acelerados procesos de "hibridación cultural" que hacen imposible sostener correlaciones fuertes entre tipos culturales, incluyendo las identidades y las estructuras sociales tal como eran entendidas durante el apogeo del paradigma industrial. La desestabilización de las convicciones ideológicas y religiosas, aunadas al sincretismo de símbolos y la creciente popularización de prácticas antes exclusivas para clases sociales bien definidas, insinúan la configuración de identidades con múltiples puntos de referencia, como nuevas formas de actuar en un mundo

5. Ilustra esto, y lo señalado antes respecto a las "comunidades imaginadas", el caso de las llamadas "tribus urbanas". En ellas, grupos de jóvenes se identifican de manera más o menos sólida entre sí, con base en rasgos estéticos y éticos compartidos, sostenidos y difundidos de manera mediata: música, reuniones esporádicas o redes sociales en internet. 
heterogéneo, donde los Otros son muchos, diversos, y los discursos suelen parecer contradictorios (García Canclini, 1995).

Se puede afirmar que en las condiciones culturales de hoy, las identidades ya no se asen a centros fijos: las categorías socioculturales tienden a ser dúctiles, más plásticas. Hay grupos "minoritarios" constantemente bregando por deconstruir las viejas nociones de identidad. En esas condiciones, convivimos diariamente con variadas posiciones, debemos constantemente codificar montañas de información y discursos heteróclitos, al punto de que las formas estereotipadas de comprender la realidad, de darle sentido, se tornan obsoletas o rayan en fundamentalismos que buscan preservar viejos órdenes.

En las actuales experiencias culturales las identidades ya no se afirman en centros referenciales estables: más bien tienden a configurarse desde la divergencia y el constante cambio, contradiciendo así radicalmente cualquier intento de acotar con nombres fijos e inmutables, la intuición del ser humano.

\section{Conclusiones}

Con base en los postulados psicoanalíticos pergeñados en el inicio de este trabajo, observamos cómo cierto sentido-de-la-identidad y la cultura se contradicen mutuamente en la dinámica del deseo: una búsqueda que se desdobla a través de atajos y vericuetos simbólicos. Esto nos permite recuperar el carácter indefinido de las identidades y reconocer su básica configuración altero-simbólica, esto es, sociocultural.

En ese sentido, la identidad aparece en los sistemas sociales entramándose con lugares y roles funcionales dotados de sentido pero no estables para siempre.

Así, metafóricamente el relato de los Vencedores en Apocalipsis nos informa que en situaciones críticas el advenimiento apocalíptico de una nueva ciudad, es decir, de una nueva configuración matricial del sentido humano, permite la renovación de nombres, reconocimiento e identidades.

En las sociedades occidentales del siglo XXI, se estaría experimentando el paulatino arribo de un sistema social basado en la transacción de los conocimientos y la ruptura de viejos estatutos y lugares funcionales, bajo la metafórica forma de sociedades en red como modelo organizacional incluso para las nuevas ciudades. De esta manera los límites otrora vigentes cambian y las identidades humanas flotan en aguas complejas, asidas de relaciones antes quizá impensables. Por ello las identidades van adquiriendo una apariencia más metamorfósica que estereotipada. Los Nombres ya no pueden entenderse como atributos fijos, sino como metáforas, como insinuaciones que no garantizarían sentidos estables pero tampoco abandono, sino partos 
cotidianos que apuran la necesidad de nuevos Nombres para las identidades. Vivimos, pues, experiencias culturales cotidianamente apocalípticas, en las que constantemente preguntamos ¿qué nombre tendremos ahora?

\section{Bibliografía}

Brown, E, Catalano, G. y Taylor, P. (2001). "Más allá de las ciudades mundiales: América Central en un espacio de flujos globales", en Revista Espacios, San José, $\mathrm{n}^{\circ} 15, \mathrm{pp} .38-45$.

Cilento, Alfredo (2001). "Metrópolis y globalización", en Fermentum, Mérida, n 11, pp. 242-255.

Corbí, Mariano (1996). Religión sin religión, Madrid: Ed. PPC.

Dor, Joel (1998). Introducción a la lectura de Lacan II. La estructura del sujeto, Barcelona: Ed. Gedisa.

Escuela Bíblica de Jerusalén (1975). Biblia de Jerusalén, Bilbao: Ed. Desclée de Brouwer.

García Canclini, Néstor (1995). Culturas Hibridas. Estrategias para entrar y salir de la Modernidad, Buenos Aires: Ed. Sudamericana.

Hernández, José (coordinador) (1996). Gran Diccionario de Psicología, Madrid: Ediciones del Prado.
Lacan, Jacques (2005). Escritos, Buenos Aires: Ed. Siglo XXI.

Malina, Bruce (1995). El mundo del Nuevo Testamento, Navarra: Ed. Verbo Divino.

Malina, Bruce (2000). The New Jerusalem in the Revelation of John, Minnesota: The Liturgical Press.

Minsky, Rosalind (2000). Psicoanálisis y Cultura, Madrid: Ed. Cátedra.

Morillas, Luis (1994). La Sociedad del Conocimiento. Cuadernos "Institut de Teologia Fonamental", http: //www.fespinal. com/espinal/itf/quaditf.htm 19 de noviembre de 2003.

Nivón, Eduardo (2000). "Conexiones urbanas: cultura, metrópolis, globalización”, en Sociológica, México DF, n 15, pp. 115-142.

Sakaiya, Taichi (1995). Historia del Futuro: la Sociedad del Conocimiento, Santiago: Ed. Andrés Bello.

Sarup, Madan (1993). An introductory Guide to Post-structuralism and Postmodernism, Londres: Harvester Wheatsheaf.

Stegemann, Ekkehard y Stegemann, Wolfgang (2001). Historia social del Cristianismo primitivo. Navarra: Ed. Verbo Divino. 